\title{
Causes and Implications of Extreme Atmospheric Moisture Demand during the Record-Breaking 2011 Wildfire Season in the Southwestern United States*
}

\author{
A. Park Williams, ${ }^{a}$ Richard Seager, ${ }^{\mathrm{b}}$ Max Berkelhammer,${ }^{\mathrm{c}}$ Alison K. Macalady, ${ }^{\mathrm{d}, \mathrm{e}}$ \\ Michael A. Crimmins, ${ }^{\mathrm{f}}$ Thomas W. Swetnam, ${ }^{\mathrm{e}}$ AnNA T. Trugman, ${ }^{\mathrm{g}}$ \\ Nikolaus Buenning, ${ }^{\mathrm{h}}$ Natalia Hryniw, ${ }^{\mathrm{i}}$ Nate G. McDowell, ${ }^{\mathrm{j}}$ \\ DAVID NOONE, ${ }^{\mathrm{c}}$ ClAUdia I. MORA, ${ }^{\mathrm{j}}$ AND THOM RAHN ${ }^{\mathrm{j}}$ \\ ${ }^{a}$ Division of Biology and Paleo Environment, Lamont-Doherty Earth Observatory, Columbia University, \\ Palisades, New York \\ ${ }^{\mathrm{b}}$ Division of Ocean and Climate Physics, Lamont-Doherty Earth Observatory, Columbia University, \\ Palisades, New York \\ ${ }^{\mathrm{c}}$ Department of Atmospheric and Oceanic Sciences, and Cooperative Institute for Research in \\ Environmental Sciences, University of Colorado Boulder, Boulder, Colorado \\ ${ }^{\mathrm{d}}$ School of Geography and Development, The University of Arizona, Tucson, Arizona \\ ${ }^{\mathrm{e}}$ Laboratory of Tree-Ring Research, The University of Arizona, Tucson, Arizona \\ ${ }^{\mathrm{f}}$ College of Agriculture and Life Sciences, The University of Arizona, Tucson, Arizona \\ ${ }^{\mathrm{g}}$ Department of Atmospheric and Oceanic Sciences, Princeton University, Princeton, New Jersey \\ ${ }^{\mathrm{h}}$ Department of Earth Sciences, University of Southern California, Los Angeles, California \\ ${ }^{\mathrm{i}}$ Department of Atmospheric Sciences, University of Washington, Seattle, Washington \\ ${ }^{\mathrm{j}}$ Earth and Environmental Sciences Division, Los Alamos National Laboratory, Los Alamos, New Mexico
}

(Manuscript received 14 February 2014, in final form 11 August 2014)

\begin{abstract}
In 2011, exceptionally low atmospheric moisture content combined with moderately high temperatures to produce a record-high vapor pressure deficit (VPD) in the southwestern United States (SW). These conditions combined with record-low cold-season precipitation to cause widespread drought and extreme wildfires. Although interannual VPD variability is generally dominated by temperature, high VPD in 2011 was also driven by a lack of atmospheric moisture. The May-July 2011 dewpoint in the SW was 4.5 standard deviations below the long-term mean. Lack of atmospheric moisture was promoted by already very dry soils and amplified by a strong ocean-to-continent sea level pressure gradient and upper-level convergence that drove dry northerly winds and subsidence upwind of and over the SW. Subsidence drove divergence of rapid and dry surface winds over the SW, suppressing southerly moisture imports and removing moisture from already dry soils. Model projections developed for the fifth phase of the Coupled Model Intercomparison Project (CMIP5) suggest that by the 2050s warming trends will cause mean warm-season VPD to be comparable to the recordhigh VPD observed in 2011. CMIP5 projections also suggest increased interannual variability of VPD, independent of trends in background mean levels, as a result of increased variability of dewpoint, temperature, vapor pressure, and saturation vapor pressure. Increased variability in VPD translates to increased probability of 2011-type VPD anomalies, which would be superimposed on ever-greater background VPD levels. Although temperature will continue to be the primary driver of interannual VPD variability, 2011 served as an important reminder that atmospheric moisture content can also drive impactful VPD anomalies.
\end{abstract}

\footnotetext{
* Supplemental information related to this paper is available at the Journals Online website: http://dx.doi.org/10.1175/JAMC-D14-0053.s1.
}

Corresponding author address: A. Park Williams, Division of Biology and Paleo Environment, Lamont-Doherty Earth Observatory, 61 Rte. 9W, Palisades, NY 10964.

E-mail: williams@ldeo.columbia.edu

\section{Introduction}

The southwestern United States (SW) experienced extreme drought in 2011, related at least in part to a $\mathrm{La}$ Niña event in the tropical Pacific Ocean (Rupp et al. 2012; Hoerling et al. 2013; Seager et al. 2014a). The 2011 SW drought event was accompanied by record-breaking total burned area (Williams et al. 2014) and record-size 
"megafires" in the forests of eastern Arizona and northern New Mexico. Extreme drought and wildfire conditions prompted widespread concern as to whether the anomalous 2011 conditions foreshadowed continued intensification of regional drought-driven wildfires in the SW as a result of greenhouse warming (e.g., Miller 2012; Nijhuis 2012).

Temperature has been shown to influence wildfire behavior in the SW by positively influencing drought (e.g., Westerling et al. 2006; Littell et al. 2009; Abatzoglou and Kolden 2013). The effect of temperature on drought operates through an exponential forcing on atmospheric moisture demand, or vapor pressure deficit (VPD) (Anderson 1936; Williams et al. 2013, 2014). VPD is defined as atmospheric saturation vapor pressure (the water vapor holding capacity, which is purely a function of temperature) minus actual vapor pressure. Therefore, the influence of temperature on drought conditions can be mitigated or amplified by variations in atmospheric moisture content. Important is that temperature exponentially influences VPD via its Clausius-Clapeyron effect on saturation vapor pressure.

In 2011, a very large burned area in the SW co-occurred with a high moisture deficit (driven by high VPD and low precipitation), consistent with the well-known positive correlation between drought and wildfire in the region (e.g., Swetnam and Betancourt 1990, 1998; Westerling et al. 2003, 2006; Westerling and Swetnam 2003; Littell et al. 2009; Abatzoglou and Kolden 2013; Williams et al. 2013, 2014). The causes of low cold-season precipitation in 2010/11 (which only reached extreme anomalies in Texas, eastern New Mexico, and Mexico) have been diagnosed (Hoerling et al. 2013; Seager et al. 2014a), but causes of extreme warm-season VPD have not. Here, we diagnose the large-scale climate processes that resulted in exceptionally high VPD in 2011. We then evaluate modeled projections to better understand whether projected trends in background mean climate resemble the 2011 climate state in any important respects. We also evaluate projected interannual variability of SW VPD and its subcomponents to determine whether the likelihood of extreme 2011-like excursions of VPD from expected background levels may change in the future.

\section{Data and methods}

We define the SW as the areas of Arizona, New Mexico, Texas, Oklahoma, Colorado, and Utah that lie south of $38^{\circ} \mathrm{N}$, north of $28.5^{\circ} \mathrm{N}$, and west of $100^{\circ} \mathrm{W}$ (as in Williams et al. 2014). We used the $\sim 4-\mathrm{km}$ gridded monthly (1895-2014) Parameter-Elevation Regressions on Independent Slopes Model (PRISM) dataset developed at Oregon State University (accessed in August 2014) to evaluate precipitation, maximum daily temperature $T_{\max }$, minimum daily temperature $T_{\min }$, dewpoint, and VPD anomalies [VPD is calculated as in Williams et al. (2013)]. Precipitation and temperature data come from the latest version of the PRISM dataset (http://www.prism.oregonstate.edu), but dewpoint data come from the previous version (http://oldprism.nacse. org) because dewpoint data are not yet included in the new dataset. We calculate VPD using temperature from the old dataset through 2013 to be consistent with the dewpoint data. We calculate 2014 VPD using newdataset temperature because the old-dataset temperature record ends in 2013. Although PRISM may not be ideal for evaluating long-term trends or temporal anomalies at some specific locations or regions (e.g., Hamlet and Lettenmaier 2005), Williams et al. (2014) demonstrate that PRISM climate records for the SW are comparable to those calculated using a wide variety of data products. An exception is for records of atmospheric moisture (dewpoint) prior to 1961, when stationbased humidity measurements were rare. We therefore report dewpoint and VPD anomalies relative to both the post-1895 and post-1961 periods.

In addition, we accessed surface wind speed (hourly) and soil moisture (monthly) data gridded at $0.125^{\circ}$ resolution from the North American Land Data Assimilation System project, phase 2 (NLDAS-2; Mitchell et al. 2004), for 1979-2014. NLDAS-2 near-surface $(10 \mathrm{~m})$ wind data are based upon the National Centers for Environmental Prediction 3-hourly, 32-km North American Regional Reanalysis (NARR), produced using an assimilation of surface measurements, radiosonde data, and atmospheric modeling (Mesinger et al. 2006). For soil moisture, we used NLDAS-2 data modeled with the "Noah" land surface model (Xia et al. 2012). We also evaluated three-dimensional reanalysis climate data using the Modern-Era Retrospective Analysis for Research and Applications (MERRA; Rienecker et al. 2011). The geographic resolution of MERRA data ranges from $0.5^{\circ}$ to $1.25^{\circ}$, and the span of temporal coverage is 1979-2014. Data are available at a vertical resolution of $25 \mathrm{hPa}$ from the surface to $700 \mathrm{hPa}$ and $50 \mathrm{hPa}$ for $700-100 \mathrm{hPa}$. Climate indices evaluated were the Pacific decadal oscillation (PDO; Mantua et al. 1997), the Southern Oscillation index (SOI; Trenberth 1984), and the Pacific-North American pattern [PNA; based upon Wallace and Gutzler (1981) but with the modified pointwise method described online at http:// www.cpc.ncep.noaa.gov/products/precip/CWlink/pna/ month_pna_index $2 . s h t m l]$.

We utilized the ensemble of monthly climate model projections made for the fifth phase of the Coupled 
Model Intercomparison Project (CMIP5) using the Intergovernmental Panel on Climate Change historical experiment through 2005 and the emissions scenario "RCP 8.5" for 2006-2100 (anthropogenic radiative forcing is $\sim 8.5 \mathrm{~W} \mathrm{~m}^{-2}$ by 2100; Moss et al. 2010; van Vuuren et al. 2011). A list of the 37 models considered is provided in Table S1 in the online supplemental material for this paper. For temperature, precipitation, dewpoint, and wind speed, we created monthly time series for the SW by linearly interpolating monthly climate fields to $0.25^{\circ}$ geographic resolution and calculating the mean monthly value of grid cells within the SW. We calculated monthly modeled VPD as in Williams et al. (2013). We also calculated modeled projections of the PDO index, the SOI, and the PNA index. We calculated the PDO index following Lapp et al. (2012), the PNA index using the modified pointwise method, and the SOI as the difference in surface pressure between Tahiti in French Polynesia and Darwin, Australia (Trenberth 1984). All model realizations of climate have biases in terms of mean and variance. For each variable, we standardized all model realizations of climate to a mean of 0 and a standard deviation of 1 (i.e., $z$ scores) during 19612005. We measured magnitudes of future climate changes as the ensemble-median and inner-quartile anomalies averaged across 2035-79 versus those for 1961-2005. Ensemble-median and inner-quartile differences between the two time periods were calculated by considering each model only once, regardless of the number of model runs available for each model. Multiple model runs for a given model were averaged together. For each variable and each model run, we generated 10000 pseudorandom time series that contain the modeled historical 1961-2005 lag-1 autocorrelation and variability to determine $95 \%$ and $99 \%$ confidence intervals for significant anomalies, accounting for lag-1 autocorrelation. Interannual variability of modeled SW April-June (AMJ) dewpoint, temperature, vapor pressure, saturation vapor pressure, and VPD were evaluated after removing the long-term projected trend from all modeled annual time series. The long-term projected trend for each variable was developed in four steps. First, each model run for the historic and future scenario was smoothed with a 31-yr filter. Then, all 31-yr smoothed time series were averaged together to create a single smoothed record for 1900-2099 for each model. Next, the long-term projected trend was calculated as the ensemble-median smoothed record, where decadal variability is canceled out as a result of the large number of models and multiple runs considered for many models. Last, the long-term trend was removed from each model run by linearly fitting the ensemble-median smoothed trend to each model's 1900-2099 annual time series, averaged across all runs, and then subtracting the adjusted trend from each annual time series. Variabilities of the resulting detrended time series were analyzed.

\section{Results and discussion}

\section{a. Drought anomalies in 2011}

We expect that temperature, precipitation, VPD, and dewpoint are all related and that anomalies in all of these variables influenced the anomalous drought conditions in 2011. For each variable, we identified the window of three or more consecutive months during August 2010-July 2011 for which SW conditions were most anomalous relative to 1895-2014. Figure 1 indicates that these four climate variables had strong anomalies in the months before and during the peak drought conditions and wildfire season of spring and early summer in 2011. These windows were JanuaryJuly for precipitation total (Fig. 1a), March-July for $T_{\max }$ (Fig. 1b), May-July for dewpoint (Fig. 1c), and March-July for VPD (Fig. 1d). Maps in Fig. 1 indicate that subregional anomalies for precipitation, dewpoint, and VPD exceeded 6 standard deviation units $\sigma$ in parts of eastern New Mexico, western and northern Texas, and southwestern Oklahoma. Anomalies for dewpoint were, by far, the strongest among the variables evaluated. Averaged across the SW, the May-July dewpoint anomaly was $-4.5 \sigma(-3.6 \sigma$ relative to $1961-2014)$. This dewpoint anomaly was expressed as a vapor pressure anomaly of $-3.9 \sigma$, or $-21 \%(-3.2 \sigma$, or $-20 \%$ relative to 1961-2014) and 10\% lower than the second-most anomalous May-July vapor pressure value in 1971. The $T_{\max }$ anomalies were not as severe when averaged across the SW (fifth highest on record for March-July), but anomalies reached $+4 \sigma$ in eastern New Mexico and parts of Texas and were the highest on record when averaged across the portion of the SW east of $105^{\circ} \mathrm{W}$. March-July $T_{\min }$ was also high in this portion of the SW (third highest on record).

Although March-July $T_{\max }$ and $T_{\min }$ anomalies were only +1.9 and $+1.7 \sigma$, respectively, when averaged across the SW $(+1.7$ and $+1.2 \sigma$ relative to $1961-2014)$, the March-July VPD anomaly was $+3.1 \sigma(+2.6 \sigma$ relative to 1961-2014). Part of the discrepancy between temperature and VPD anomalies was due to a disproportionately large influence of strong $T_{\max }$ anomalies in the eastern SW (caused by the exponential influence of temperature on VPD). The 2011 VPD anomaly was also strongly influenced by extremely low specific humidity, as shown in Fig. 1c. In Fig. 2, red and blue lines indicate the contributions of temperature and dewpoint variability, 

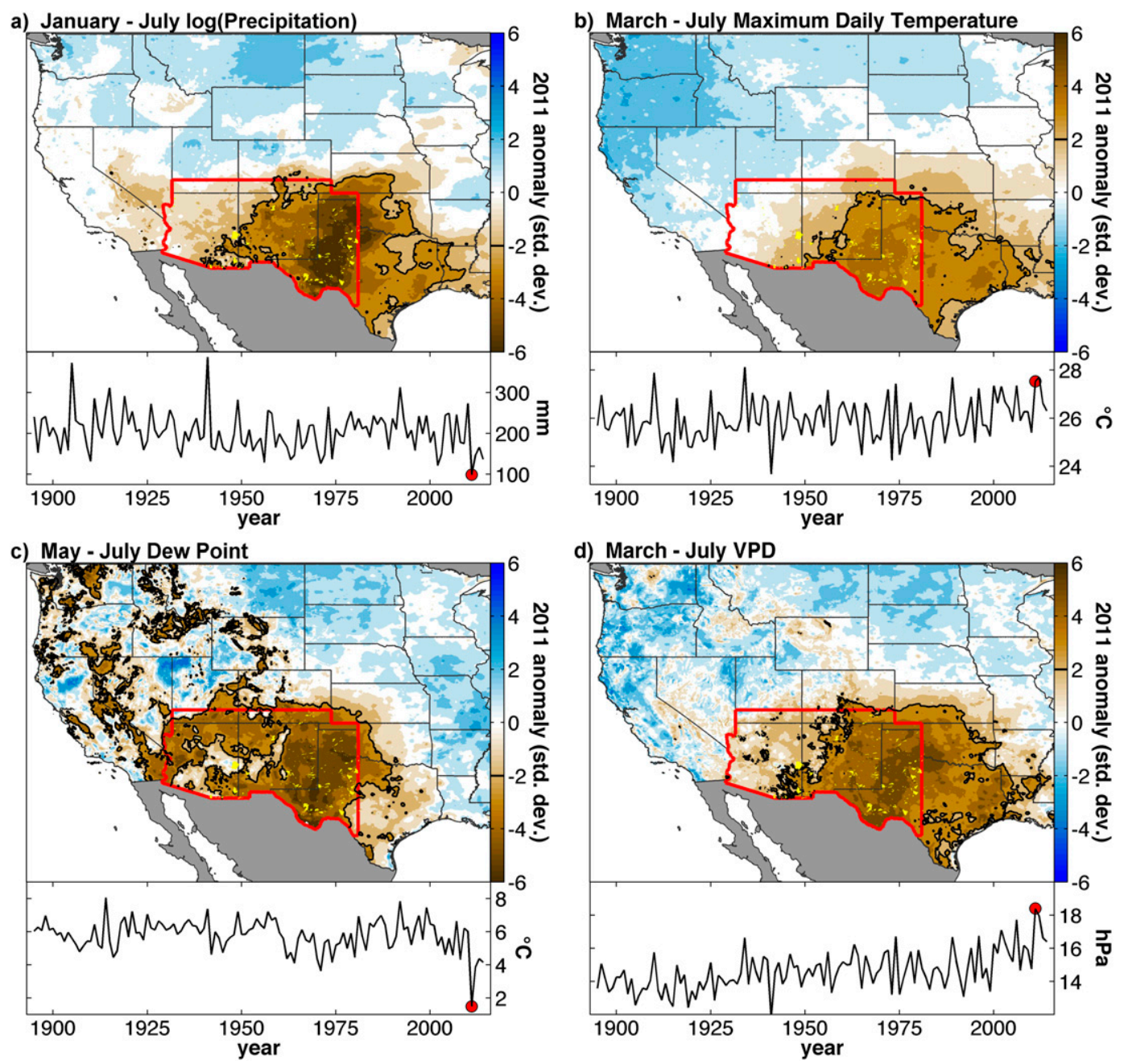

FIG. 1. Surface climate anomalies in 2011 for (a) $\log$ (precipitation), (b) daily maximum temperature, (c) dewpoint, and (d) VPD. For each variable, the period of 3-6 months during August 2010-July 2011 with the strongest anomaly in the SW is shown. Maps show spatial distributions of anomalies as standard deviations from the 1895-2014 mean. Time series show annual values averaged across the SW region, with red dots indicating 2011 values. In the maps, red polygons bound the SW, black contours represent drought anomalies of 2 standard deviations, and yellow areas indicate locations of 2011 fires (Williams et al. 2014).

respectively, toward VPD anomalies (black line) during March-July, the period during which VPD was most anomalous. Dewpoint contributions were calculated by holding monthly temperatures within each PRISM grid cell at their climatological means and only allowing dewpoint to vary. Temperature contributions were calculated oppositely. Although temperature normally dominates VPD variability in the SW (R. Seager et al. 2014, unpublished manuscript), an exceptionally low dewpoint in 2011 was responsible for $45 \%$ of the recordbreaking VPD anomaly in March-July 2011 (57\% when only May-July is considered). The powerful impact of low dewpoint on VPD in 2011 is in contrast to the more negligible impact of dewpoint anomalies during other recent temperature-driven anomalous VPD years such as 2000-02, 2006, and 2012 (Fig. 2), highlighting the uniqueness of the 2011 drought event.

\section{b. Causes of low humidity and high VPD in 2011}

Although VPD was anomalously high during all spring and summer months, we focus for the rest of this paper on AMJ, which are the three months centered within the most anomalous period. In 2011, sustained upper-level convergence occurred above and to the west (upwind) of the SW (Fig. 3b) as a result of the wave train of circulation anomalies likely associated with the La Niña sea surface temperature (SST) pattern and reduced atmospheric heating over the tropical Pacific Ocean 


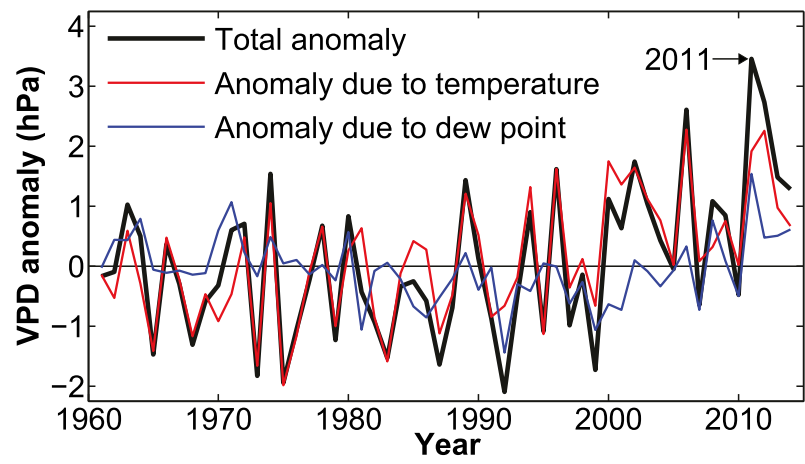

FIG. 2. March-July VPD anomalies (departure from the 19612014 mean of $15.17 \mathrm{hPa}$ ). Red and blue lines indicate partial contributions of temperature and dewpoint anomalies, respectively, toward the total anomaly (thick black line). Partial contributions of temperature and dewpoint anomalies were calculated by allowing only one variable at a time to vary from its 1961-2014 mean.

(Fig. 3h). Consistent with La Niña-like atmospheric circulation, upper-level westerly anomalies above the central and eastern Pacific Ocean were contained within cyclones straddling the equator. Poleward and east of these cyclones were enhanced upper-level anticyclonic circulation patterns that, over the North Pacific, translated into a weaker-than-normal Aleutian low (Figs. 3b,d,f). On the eastern flanks of the upper-level subtropical cyclone and midlatitude anticyclone (near the west coast of Mexico), southerly wind anomalies converged with northerly anomalies above western North America (Figs. 3b,d), forcing subsidence.

Figure $4 \mathrm{~b}$ indicates a large region over the eastern North Pacific in which upper-level $(300 \mathrm{hPa})$ convergence anomalies exceeded $2 \sigma$ (relative to 1979-2014) during AMJ 2011 across the northeastern and southeastern flanks of the North Pacific high pressure zone. In addition to the impact of upper-level convergence, the northerly flow anomaly along the North American west coast was, on its own, associated with descending motion through balances between advection of planetary vorticity and vortex stretching and between anomalous cold (northerly) advection and compressional warming. Reanalysis data indicate that AMJ 2011 vertical velocities averaged across the SW between the surface and $300 \mathrm{hPa}$ were anomalously downward (Fig. 4d), with AMJ 2011 downward velocities ranking second strongest on record according to MERRA and strongest on record according to the NARR (Mesinger et al. 2006; see online supplemental section S1). Figure 4d indicates that 2011 vertical velocity anomalies (MERRA) were spatially heterogeneous, with subsidence anomalies exceeding $2-3 \sigma$ throughout much of Arizona and New Mexico and ascending anomalies in west Texas. Figures $4 \mathrm{e}$ and $4 \mathrm{f}$ show the vertical structure of specific humidity and the northwesterly wind pattern traveling along the average low-level wind path from the coastal northeastern Pacific toward and across the SW (path indicated by the orange line in Fig. 4c). This profile view indicates that the subsidence anomalies described above were generally present throughout the atmospheric profile upwind of and over the SW (Fig. 4f).

Subsidence brings dry, high-altitude air to the surface and contributes to enhanced low-level divergence. According to NLDAS-2 hourly surface wind data, the AMJ 2011 wind speed averaged across the SW was $2.6 \sigma$ (18\%) above the 1979-2014 mean and surface wind divergence anomalies were greater than $2 \sigma$ across much of the SW (not shown). Divergence of dry, rapidly moving air over the SW worked to suppress low-level moisture fluxes from the usual sources in the subtropical Pacific and Gulf of Mexico regions (Figs. 4g,h; southerly surface moisture flux anomalies into the $\mathrm{SW}$ were from -0.5 to $-2 \sigma)$. This result is corroborated by a vaportagging experiment (see online supplemental section S2), indicating that SW atmospheric moisture transported from the subtropical Pacific and Gulf of Mexico regions was substantially reduced in 2011.

Low-level humidity in the SW was further suppressed by low evaporation rates from land that were due to very dry soils, which resulted from low precipitation in preceding months. Near-surface $(0-10 \mathrm{~cm})$ modeled soil moisture averaged across the SW was the lowest on record $(-2.1 \sigma)$, causing evapotranspiration to be the lowest on record $(-2.0 \sigma)$ despite record-breaking potential evapotranspiration $(2.2 \sigma)$ (anomalies are based on 1979-2014 NLDAS-2). On the basis of our vapor-tagging analysis, it is seen that water vapor derived from land surface evaporation in and around the SW was virtually missing from the eastern portion of the SW atmosphere in AMJ 2011 (see online supplemental section S2). Continuous exposure to dry westerly winds and high sensible heat flux due to very dry soils combined to cause record-breaking spring and early summer temperature anomalies throughout much of western Texas, further amplifying VPD in this region.

\section{c. Interrelation among variables underlying the unique 2011 conditions}

Figure 5 shows how atmospheric circulation (wind speed and geopotential height) and surface temperatures correlated with SW dewpoint (panels on left) and temperature (panels on right) during AMJ 1979-2014. There are strong similarities between the conditions typically associated with low dewpoints (Fig. 5, left) and the climate anomalies in 2011 (Fig. 3). There is less correspondence between anomalies in 2011 and the conditions typically associated with high temperature (Fig. 5, right). 

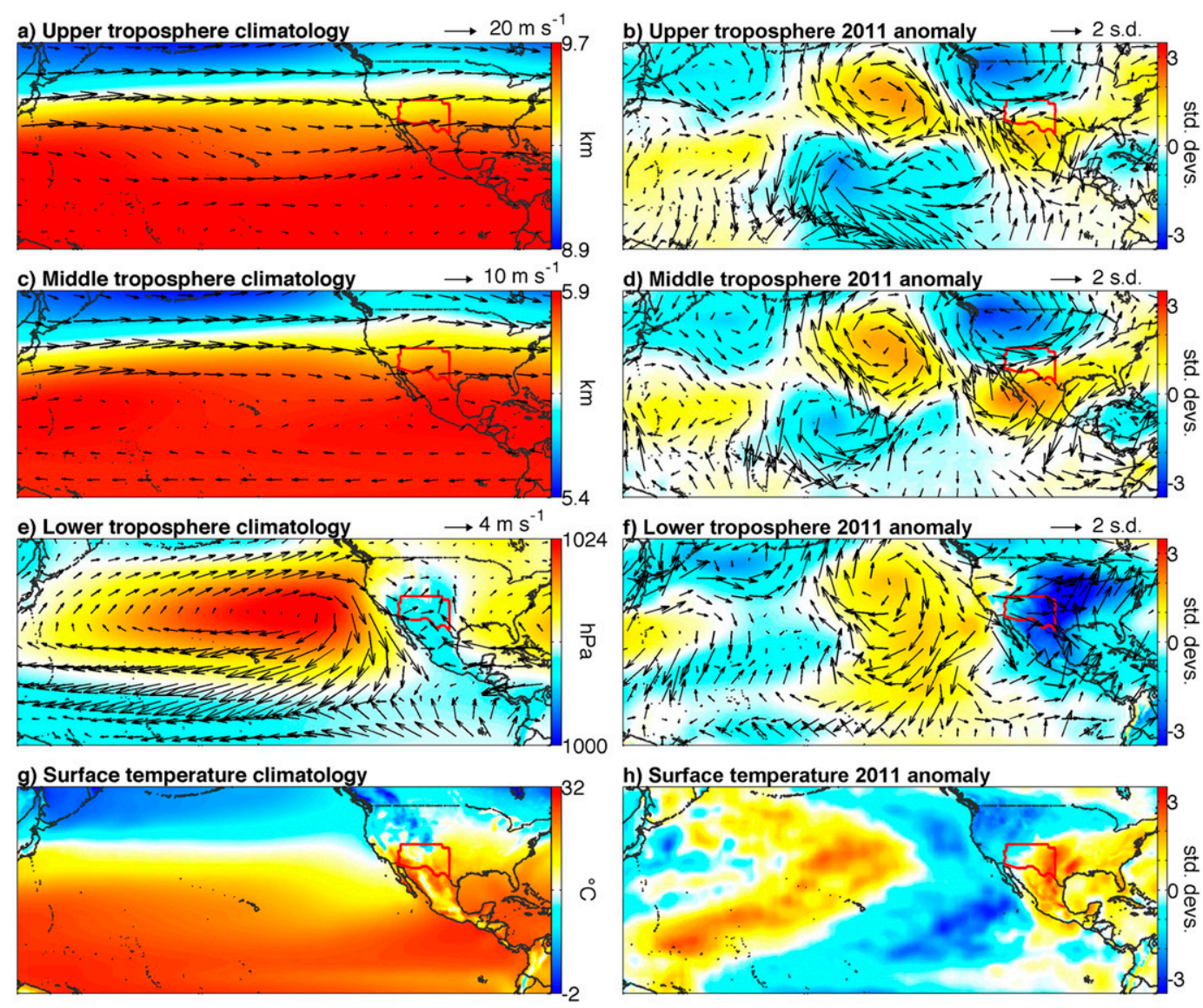

FIG. 3. April-June atmospheric circulation and surface temperature: (left) 1979-2014 means and (right) 2011 standardized anomalies. Arrow vectors show the vertically integrated wind velocity. (a),(b) The upper troposphere (300-200 hPa), where the background is the 300-hPa geopotential height. (c),(d) The middle troposphere (600$400 \mathrm{hPa}$ ), where the background is $500-\mathrm{hPa}$ geopotential height. (e),(f) The lower troposphere (surface-700 $\mathrm{hPa}$ ), where the background is SLP. $(\mathrm{g}),(\mathrm{h})$ The surface temperature.

Correspondence between the 2011 anomaly maps in Fig. 3 and the dewpoint correlation maps in Fig. 5 indicates that AMJ 2011 climate was in many ways an amplification of the same atmospheric and oceanic conditions responsible for low dewpoints in the SW during other years in recent decades. In particular, the 2011 anomaly patterns and dewpoint correlation fields share a sea level pressure (SLP) gradient between the North Pacific high and low pressure over central North America (Figs. 3f and 5e). If one considers 1961-2014, the AMJ SLP gradient SLP $_{g}$ between the North Pacific $\left(20^{\circ}-45^{\circ} \mathrm{N}, 90^{\circ}-110^{\circ} \mathrm{W}\right)$ and North America $\left(30^{\circ}-50^{\circ} \mathrm{N}\right.$, $\left.130^{\circ}-170^{\circ} \mathrm{W}\right)$ was the strongest on record in $2011(2.8 \sigma)$ and correlates negatively with AMJ dewpoint in the SW (correlation coefficient $r=-0.59$; Table 1) (see supplemental section S3 for methods to calculate $\mathrm{SLP}_{g}$ ). A strong $\mathrm{SLP}_{g}$ drives northerly winds down the North American coast, exposing the SW to anomalously dry air from the north and from above through subsidence.
Strong $\mathrm{SLP}_{g}$ and low SW dewpoint are associated with SST patterns resembling the cold phase of the PDO and La Niña (Figs. $3 \mathrm{~h}$ and $5 \mathrm{~g}$ ), in which intensified $\mathrm{SLP}_{g}$ promotes, and is reinforced by, northerly low-level wind that drives upwelling of cold water in the eastern North Pacific. The SW dewpoint may be also partially suppressed during cold-phase years because relatively cool SSTs suppress atmospheric moisture across large spatial scales. During AMJ 1961-2014, the PDO correlated positively and the SOI correlated negatively with SW dewpoint ( $r=0.47$ and -0.46 , respectively; Table 1$)$. Crimmins (2010) shows that La Niña and the PDO cold phase correspond positively to the frequency of days during which meteorological conditions are conducive to wildfire in the SW.

Another key similarity between the 2011 anomalies and the conditions that are generally associated with low SW dewpoint is a strengthened mid- and upper-level geopotential height gradient between anomalously low 
a) $300 \mathrm{hPa}$ Convergence climatology

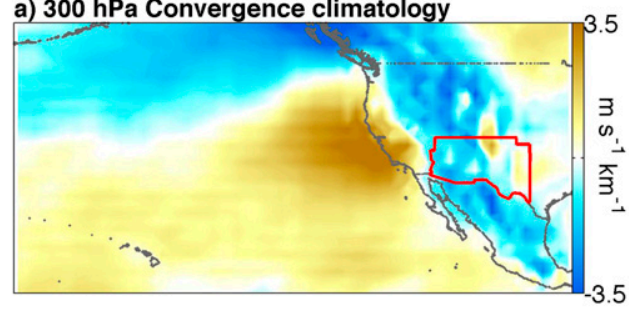

c) Vertical velocity climatology
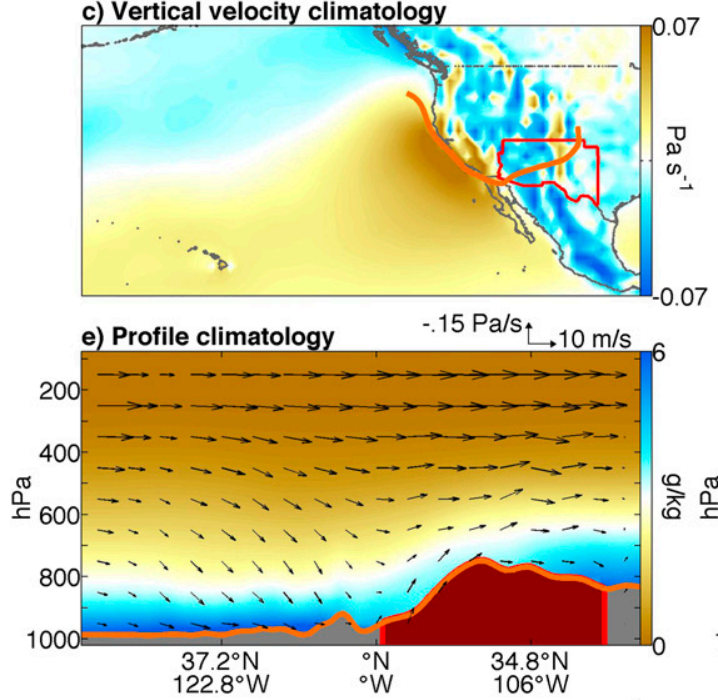

g) Vapor flux climatology
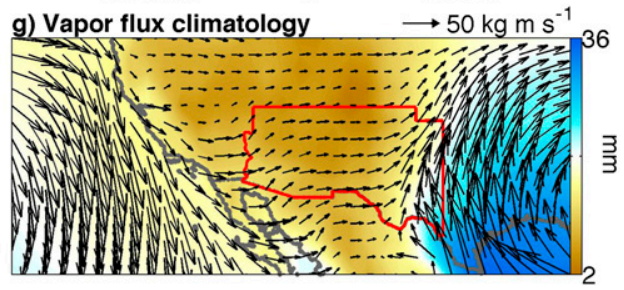

b) $300 \mathrm{hPa}$ Convergence 2011 anomaly

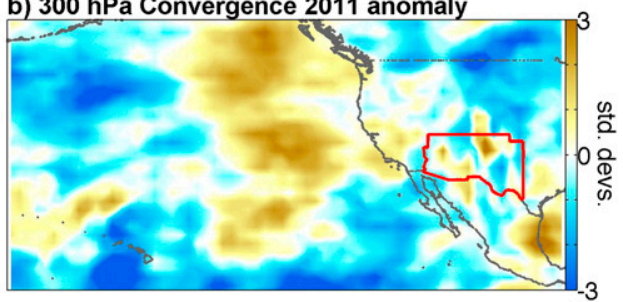

d) Vertical velocity 2011 anomaly

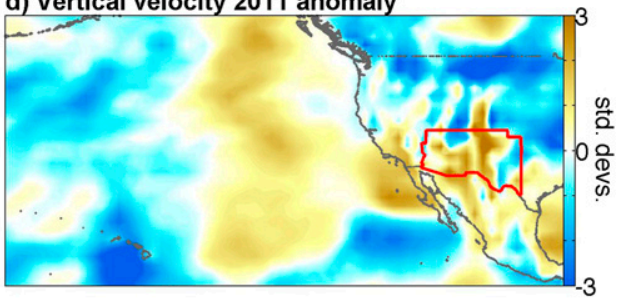

f) Profile 2011 anomaly

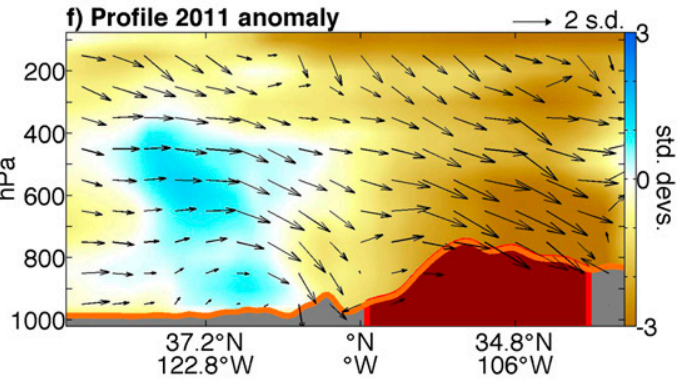

h) Vapor flux 2011 anomaly $106^{\circ} \mathrm{W}$

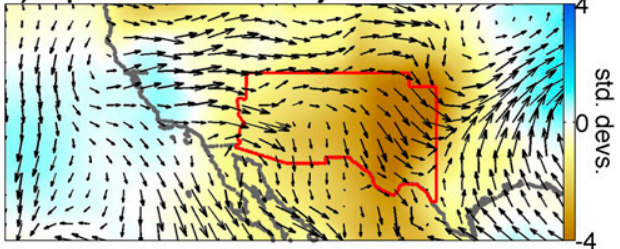

FIG. 4. April-June three-dimensional atmospheric circulation: (left) 1979-2014 means and (right) 2011 standardized anomalies. (a),(b) Convergence of wind at $300 \mathrm{hPa}$ (negative values indicate divergence). (c),(d) Vertical velocity between the surface and $300 \mathrm{hPa}$ (positive values indicate sinking motion). (e),(f) Vertical atmospheric profiles of horizontal and vertical winds (arrow vectors) and specific humidity (background) along the orange path shown in (c) from west to east. The path represents the mean trajectory of the wind passing through the central SW between the surface and $650 \mathrm{hPa}$ during April-June. The orange line represents the surface, and the maroon area bounded by red lines represents the SW region. (g),(h) Integrated atmospheric vapor flux (arrow vectors) and content (background) between the surface and $650 \mathrm{hPa}$.

heights over the U.S. Pacific Northwest and anomalously positive heights over the eastern North Pacific and western Mexico. These strong gradients promote midand upper-level convergence and subsidence anomalies upwind of and above the SW (Figs. 3b and 5a). To represent the strength of these upper-atmospheric pressure gradients and associated convergence/subsidence processes, we developed a simple geopotential height gradient index $G_{300}$ that is based upon the 300-hPa height patterns in Figs. 3b and 5a. Here, $G_{300}$ is the mean of two height gradients (gradient 1 is North Pacific minus Pacific Northwest and gradient 2 is western Mexico minus Pacific Northwest, with North Pacific defined as $35^{\circ}-50^{\circ} \mathrm{N}, 160^{\circ}-142^{\circ} \mathrm{W}$; Pacific Northwest defined as $40^{\circ}-50^{\circ} \mathrm{N}, 125^{\circ}-107.5^{\circ} \mathrm{W}$; and western Mexico defined as $\left.17.5^{\circ}-30^{\circ} \mathrm{N}, 122.5^{\circ}-97.5^{\circ} \mathrm{W}\right) ; G_{300}$ is strongly related to $\operatorname{SLP}_{g}(r=0.87$; Table 1$)$ and correlates negatively with SW dewpoint $\left(r=-0.65\right.$; Table 1). Positive $G_{300}$ tends to correspond to the negative phase of the PNA index, which tends to be favored by cold (La Niña) phases of the SOI or PDO (Table 1) (Zhang et al. 1997; Ault et al. 2011), yet may also result from internal variability.

Land surface moisture in 2011 also had a spatial anomaly pattern (Fig. 6a) that was similar to that associated with low SW dewpoint historically (Fig. 6b). In 

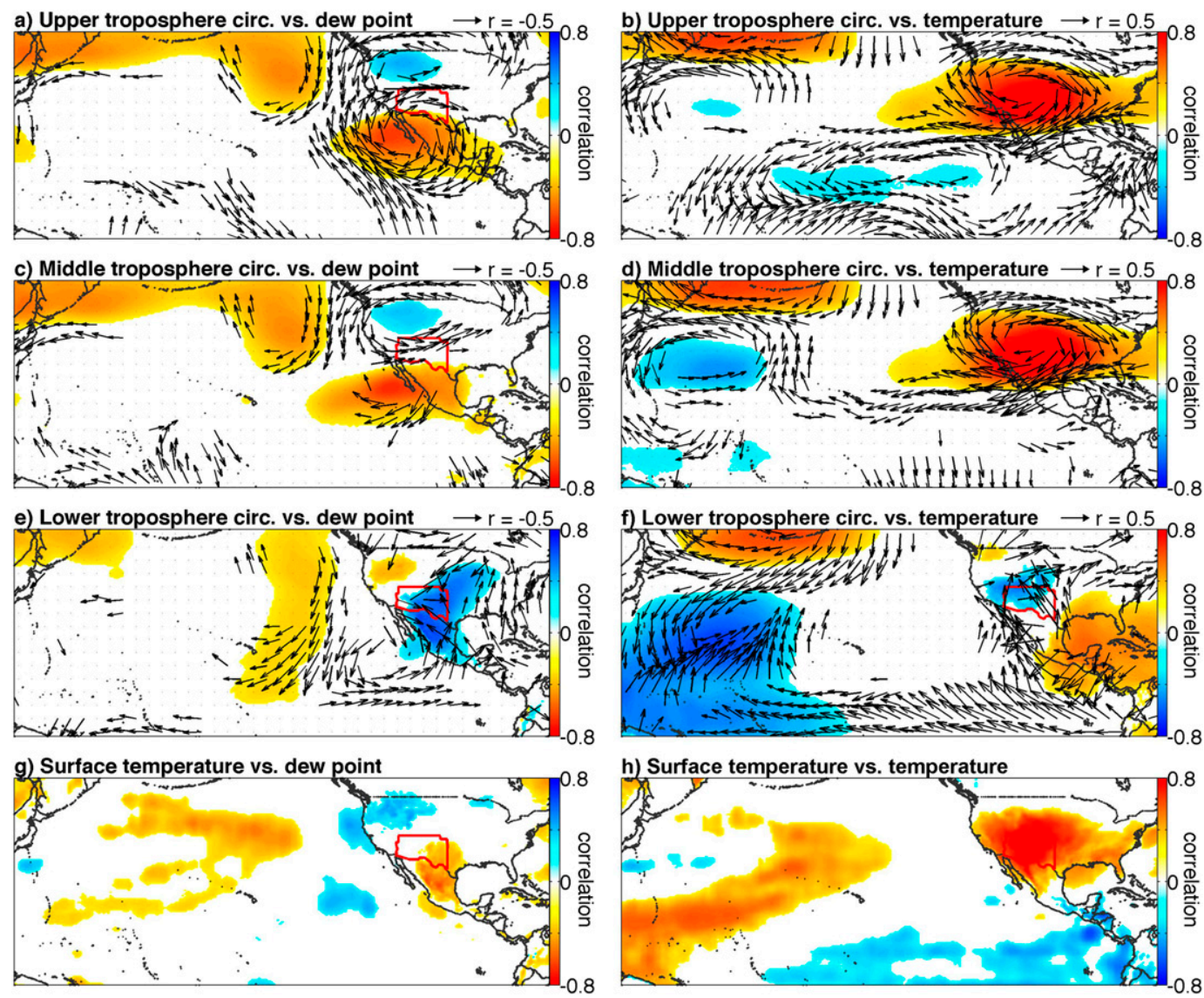

FIG. 5. April-June atmospheric circulation and surface temperature vs SW (left) dewpoint and (right) temperature. Analysis period is 1979-2014, excluding 2011 to avoid biasing correlation fields toward extreme 2011 conditions. (a), (b) The upper troposphere $(300-200 \mathrm{hPa})$, where the background is correlation with $300-\mathrm{hPa}$ geopotential height. (c),(d) The middle troposphere $(600-400 \mathrm{hPa})$, where the background is correlation with 500-hPa geopotential height. (e),(f) The lower troposphere (surface-700 hPa), where the background is the correlation with SLP. (g),(h) The surface temperature. Only correlations with $>90 \%$ confidence (accounting for lag-1 autocorrelation) are shown. Wind-vector directions and color schemes reflect conditions associated with high VPD (low dewpoint on left; high temperature on right) in the SW. Arrow vectors in (a)-(f) show the correlation with vertically integrated wind velocity.

the past, low dewpoint has corresponded to dry soil across much of the SW and northern Mexico and to wet soil in the Pacific Northwest, similar to spatial structures for precipitation and temperature 2011 anomalies in Fig. 1. This is due partly to the influences that the SOI and PDO oscillations have on the geographic distribution of winter and spring precipitation in western North America (e.g., Dettinger et al. 1998), which subsequently affect warmseason humidity and temperature (Table 1). Positive SOI and negative PDO also tend to enhance $\mathrm{SLP}_{g}$ and $G_{300}$, promoting northerly wind and cool temperatures throughout much of the west (as in Fig. 1b). Enhanced subsidence, decreased cloud shading, and increased surface wind speed combine to increase temperature and potential evapotranspiration toward the eastern $\mathrm{SW}$, however, drawing soil moisture down and increasing surface sensible heat fluxes when soil moisture is limiting, as in 2011. The resultant spatial structure of surface temperature and moisture in 2011 may have further promoted high VPD in the SW through land surface feedbacks on large-scale atmospheric circulation (e.g., enhancement of a surface heat low and tropospheric ridging) that reinforced low humidity and high surface temperature throughout much of the SW, as in the European heat wave of 2003 (e.g., Zaitchik et al. 2006; Fischer et al. 2007). Therefore, although extreme 2011-like years appear possible only when a suite of factors are in place, many of these factors are interrelated and may be largely distilled down to factors that promote dry soils (primarily low precipitation) and strong, dry wind sourced from the north (primarily $G_{300}$ and $\mathrm{SLP}_{g}$ ).

\section{d. Implications for the future}

Figure 7 shows CMIP5 ensemble-median (red bars) and inner-quartile climate-model projections of climate 
TABLE 1. Correlation matrix for 11 interrelated climate variables that influenced extreme SW drought in 2011. All climate records represent April-June except precipitation (October-June). Correlations represent 1961-2014 except for those involving $G_{300}$ or soil moisture soil $m$ (1979-2014). Boldface values indicate correlations that are significant above the $95 \%$ confidence level, accounting for lag- 1 autocorrelation. NLDAS-2 wind speed data were extended to 1961 using the Sheffield et al. (2006) dataset.

\begin{tabular}{|c|c|c|c|c|c|c|c|c|c|c|c|}
\hline & VPD & $T_{\text {avg }}$ & $T_{\mathrm{dew}}$ & $\mathrm{SLP}_{g}$ & $G_{300}$ & Soil $_{m}$ & Precipitation & Wind & PDO & SOI & PNA \\
\hline VPD & 1.00 & 0.85 & -0.58 & 0.30 & 0.27 & -0.89 & -0.75 & 0.40 & -0.19 & 0.32 & -0.28 \\
\hline$T_{\text {avg }}$ & - & 1.00 & -0.09 & 0.00 & -0.09 & -0.66 & -0.51 & 0.07 & 0.01 & 0.09 & -0.15 \\
\hline$T_{\text {dew }}$ & - & - & 1.00 & -0.59 & -0.65 & 0.79 & 0.68 & -0.65 & 0.47 & -0.46 & 0.37 \\
\hline $\mathrm{SLP}_{g}$ & - & - & - & 1.00 & 0.87 & -0.49 & -0.22 & 0.60 & -0.32 & 0.39 & -0.59 \\
\hline$G_{300}$ & - & - & - & - & 1.00 & -0.51 & -0.34 & 0.84 & -0.39 & 0.33 & -0.56 \\
\hline Soil $_{m}$ & - & - & - & - & - & 1.00 & 0.90 & -0.72 & 0.39 & -0.46 & 0.50 \\
\hline Precipitation & - & - & - & - & - & - & 1.00 & -0.50 & 0.36 & $-\mathbf{0 . 4 0}$ & 0.34 \\
\hline Wind & - & - & - & - & - & - & - & 1.00 & -0.35 & 0.49 & -0.49 \\
\hline PDO & - & - & - & - & - & - & - & - & 1.00 & -0.34 & 0.57 \\
\hline SOI & - & - & - & - & - & - & - & - & - & 1.00 & $-\mathbf{0 . 3 9}$ \\
\hline PNA & - & - & - & - & - & - & - & - & - & - & 1.00 \\
\hline
\end{tabular}

anomalies during 2035-79 (relative to 1961-2005) for the variables that appear to have contributed to the extreme 2011 VPD event in the SW. Black bars show 2011 anomalies for comparison. During AMJ, the mean $\mathrm{SW}$ temperature anomaly is projected to be $+2.87^{\circ} \mathrm{C}$ in 2035-79 (Fig. 7a). The projected warming trend drives an ensemble-median VPD anomaly of $+3.01 \mathrm{hPa}$ during 2035-79 (19.5\% higher than for 1961-2005) (Fig. 7b).

The other component of VPD, atmospheric moisture content, is also projected to rise (Fig. 7c) in accordance with general increases in atmospheric and ocean temperatures globally. Increasing atmospheric moisture content mitigates the effect of warming on VPD, but the exponential Clausius-Clapeyron relationship between temperature and saturation vapor pressure dictates that VPD would increase as a result of warming even if atmospheric moisture content increased enough to maintain constant relative humidity (RH; Anderson 1936). In reality, models do not project atmospheric moisture increases to be substantial enough to maintain stable RH levels in the SW (Fig. 7d). This is partly because of limited surface moisture in the SW but also because of moisture divergence trends in the mean state of the SW atmospheric circulation (Seager et al. 2014b). Suppressed increases in atmospheric moisture content work to amplify the effects of warming on SW VPD.

It appears that the processes involved in suppressing projected increases in atmospheric moisture content were also at work in suppressing 2011 atmospheric moisture content in multiple respects. In considering the climate variables identified in sections $3 b$ and $3 c$ as generally associated with SW dewpoint variability and also anomalous in $2011\left(\mathrm{SLP}_{g}, G_{300}\right.$, October-June precipitation, PDO, SOI, PNA, and wind speed), Figures $7 \mathrm{e}-\mathrm{k}$ indicate that ensemble-median projected trends share the same sign as 2011 anomalies for all variables evaluated (although the projected trends are very weak for some variables). Although the ensemblemedian trend in $\mathrm{SLP}_{g}$ is relatively weak, the spatial pattern of ensemble-median projected SLP trends is similar to that associated with low SW dewpoint (Figs. 3 and 5), and 35 of the 36 models evaluated converge upon increased SLP over the northeastern Pacific Ocean in the region of the Aleutian low (see supplemental Fig. S4). The projections evaluated here suggest that some of the large-scale processes projected to suppress future increases in SW atmospheric moisture content in the SW were also at work in 2011.

Model projections of increasing atmospheric moisture imply that the extremely low atmospheric moisture levels observed in 2011 and the multidecade decline that began in the early 1990s should be becoming increasingly improbable (Fig. 8a). The observed decadal trends shown in Fig. 8 a are undoubtedly dominated by internal climate variability, but models within the CMIP5 archive do not tend to simulate the observed level of multidecadal internal variability. During 1990 2014 , observed AMJ dewpoint declined by $3.82^{\circ} \mathrm{C}$ (according to the linear trend), corresponding to a vapor pressure decline of $20.9 \%$. Histograms in Figs. $8 \mathrm{~b}$ and $8 \mathrm{c}$ show the CMIP5 ensemble distribution of linear changes in dewpoint and vapor pressure, respectively, during all possible $25-\mathrm{yr}$ periods of the historical scenario (18502005). Only one of the 30 models with adequate data (Commonwealth Scientific and Industrial Research Organisation, Mark 3.6.0) simulates a 25-yr dewpoint decline of more than $3.82^{\circ} \mathrm{C}$, and this occurs at the beginning of the twentieth century in just 1 of 10 historical runs. This is also the only model that simulates a $25-\mathrm{yr}$ period when vapor pressure declines by $20.9 \%$ or more. The mismatch between observed and modeled decadal variability in atmospheric moisture content indicates that either the ongoing decline in SW atmospheric moisture is a truly exceptional event or that the CMIP5 
a) 2011 AMJ soil moisture anomaly

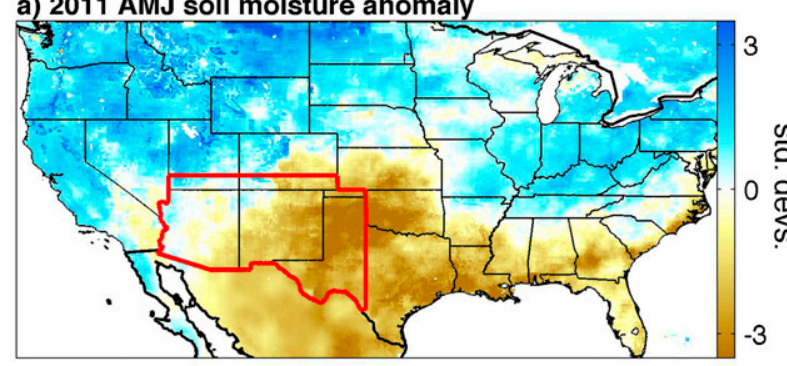

b) correlation: AMJ soil moisture vs. SW dew point

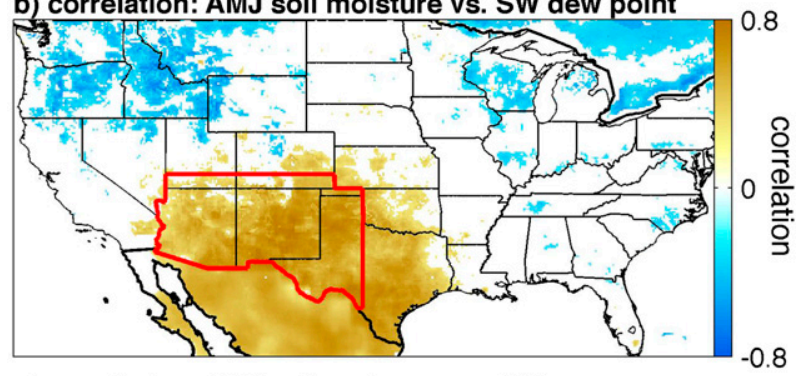

c) correlation: AMJ soil moisture vs. SW temperature

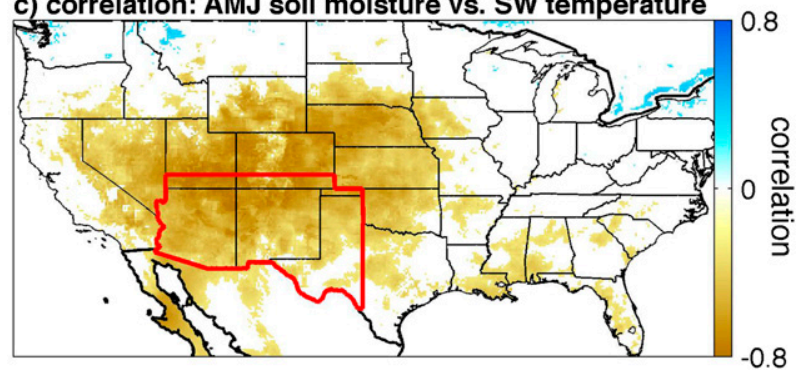

FIG. 6. (a) April-June 0-10-cm soil moisture anomaly during 2011, and correlations with SW (b) dewpoint and (c) temperature. Analysis period is 1979-2014, excluding 2011 to avoid biasing correlation fields toward extreme 2011 conditions. Color scheme in all panels is organized such that brown colors correspond to low soil moisture in the SW. In (b) and (c), only correlations with $>90 \%$ confidence (accounting for lag-1 autocorrelation) are shown.

ensemble largely misrepresents decadal atmospheric moisture variability in the SW. If models do indeed underrepresent decadal variability in SW atmospheric moisture, it would imply that repeated occurrences of 2011-like atmospheric moisture anomalies are more likely than are projected by the CMIP5 ensemble.

Enhanced probabilities of occurrence of 2011-type atmospheric moisture anomalies are also suggested by an analysis of projected interannual variability in dewpoint and vapor pressure (Figs. 9a,b). Even after removal of long-term projected trends (such as that shown in Fig. 8), the CMIP5 ensemble projects interannual variability of AMJ dewpoint to be significantly higher ( $p<0.01$ on the basis of a $t$ test) during 2035-79 than in 1961-2005 (Fig. 9a; standard deviation anomalies in Fig. 9 use a 1961-2005 baseline). Projected increases in dewpoint variability translate to even larger increases in

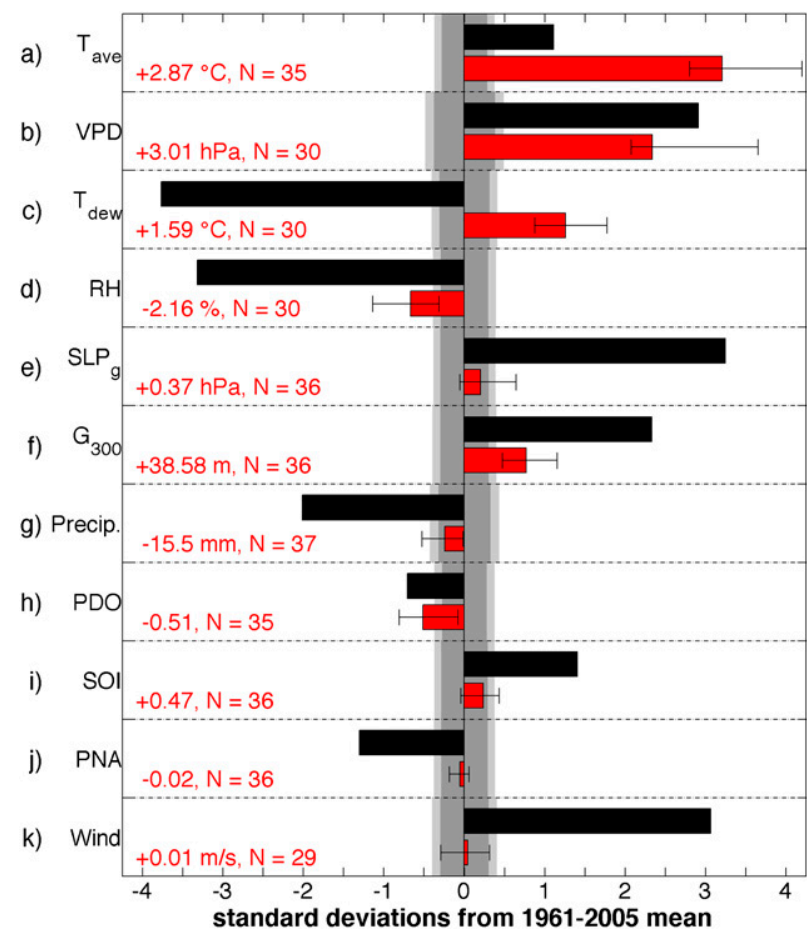

FIG. 7. CMIP5 climate projections. Red bars show the ensemble median of the average annual anomaly during 2035-79 relative to 1961-2005. Whiskers show the ensemble inner-quartile anomalies. Black bars show the 2011 anomalies. Projected mean anomalies in 2035-79 that fall within the dark and light gray areas are not significant at the $95 \%$ and $99 \%$ confidence levels, respectively, accounting for the lag-1 autocorrelation in the model data. The units of anomalies are standard deviations from the 1961-2005 mean, based on variability during that period. Red values on the left indicate absolute values of the ensemble-median anomalies based upon 1961-2005 observed variability. All variables represent April-June except for precipitation, which represents October-June. The number of models with required data is indicated by $N$.

vapor pressure variability because of the increase in mean dewpoint and the exponential relationship between dewpoint and vapor pressure. In comparing the two simulated time periods, the ensemble-median frequency of years when vapor pressure anomaly (departure from projected trend) is negative enough to positively force VPD by at least $10 \%$ of the 1961-2005 mean (requiring a vapor pressure anomaly of $\leq-2.4 \sigma$ ) is seen to be 3 times as high in 2035-79 as in 1961-2005 (Fig. 9b).

Models also tend to project slight increases in AMJ temperature variability (Fig. 9c). Although these increases are smaller than those for dewpoint, the nonlinear Clausius-Clapeyron relation leads to significantly increased variability in saturation vapor pressure because of warming. Ensemble-median variability in saturation vapor pressure increases by $30 \%$, as compared with $20 \%$ for vapor pressure. In comparing the two time 

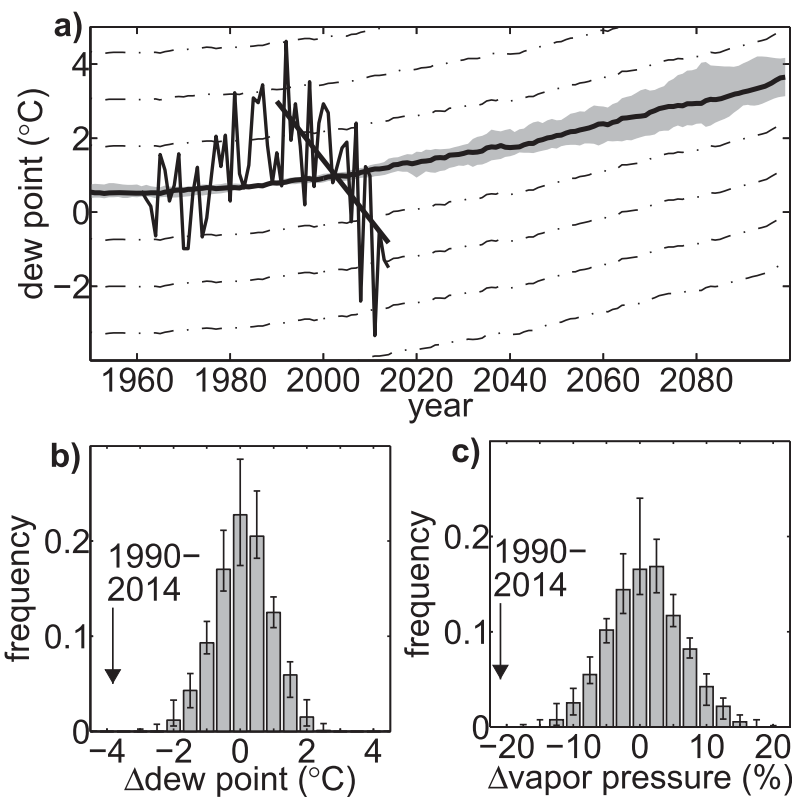

FIG. 8. Observed AMJ dewpoint in the SW during 1961-2014 overlaid on the CMIP5 ensemble-median (thick black curve) and inner-quartile (gray shading) trends. Dotted curves indicate standard deviation departures from the ensemble-median trend, based on 1961-2005 observed variability. Model time series were adjusted to exhibit observed variability during 1961-2005 (the period when the observed record overlaps with the historical model simulations) and the observed mean during 1961-2014. Arrows in (b) and (c) indicate observed changes in dewpoint and vapor pressure during $1990-2014$ ( $-3.82 \mathrm{hPa}$ and $-20.9 \%$, respectively).

periods, the ensemble-median frequency of years when AMJ saturation vapor pressure anomaly is positive enough to positively force VPD anomalies by at least $10 \%$ (requiring a saturation vapor pressure anomaly of $\geq 1.3 \sigma$ ) of the $1961-2005$ mean is projected to increase by approximately $84 \%$ (Fig. 9d). While this relative change is much less than the threefold increase projected for vapor pressure (Fig. 9a), the interannual variability of saturation vapor pressure is approximately $65 \%$ larger than the variability of actual vapor pressure, dictating that temperature variability will continue to be the dominant driver of VPD departures from the background trend (Fig. 9f). Nonetheless, 2011 serves as an example of the potential for extreme vapor pressure anomalies to have impactful effects on VPD. Although models generally do not simulate dewpoint and vapor pressure anomalies that are as strong as those observed in 2011, projections of increased interannual variability for these variables suggests an increasing likelihood of repeated 2011-like events in which humidity is substantially reduced relative to the projected trend, contributing to extremely positive VPD anomalies.

Combining the lessons learned from analyses of projected trends and variability, it is clear from Fig. 7 that
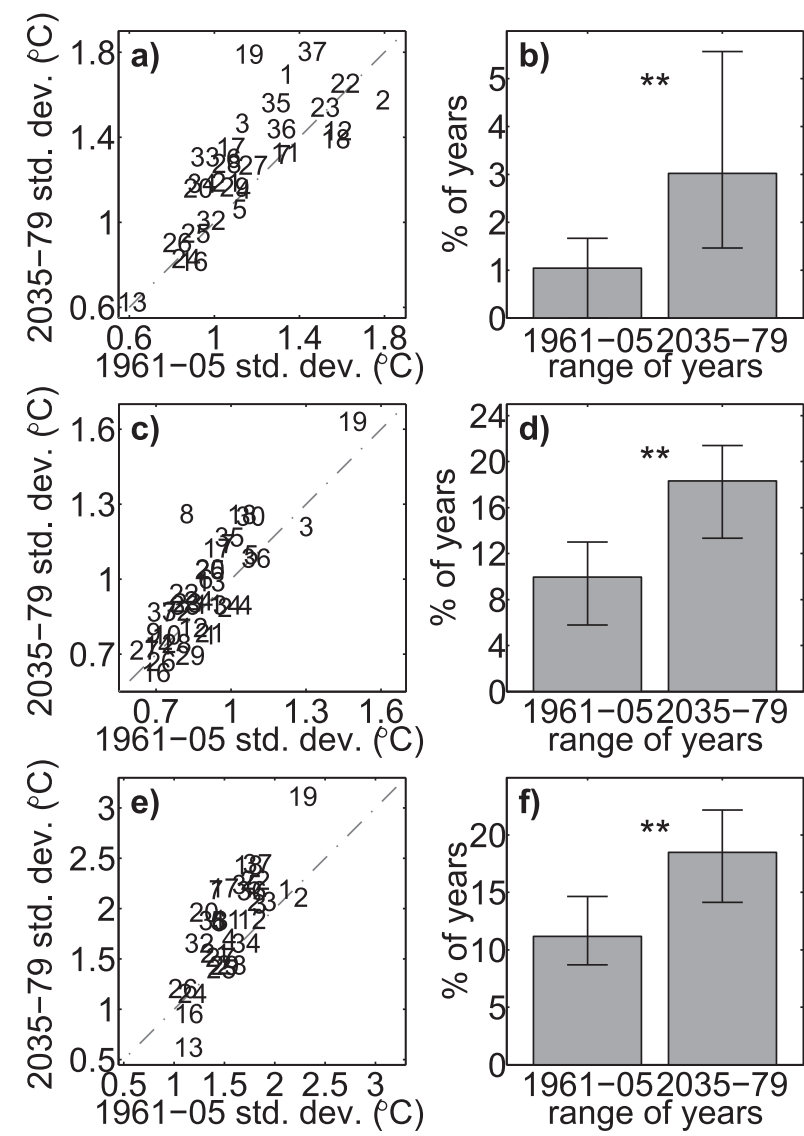

FIG. 9. Modeled interannual variability for historic and projected scenarios. Scatterplots compare interannual variability during 2035-79 with that of 1961-2005 for AMJ (a) dewpoint, (c) temperature, and (e) dewpoint depression (temperature - dewpoint). Each number corresponds to a CMIP5 model, as listed in Table S1 of the supplemental material. Variability is calculated after the long-term trend is removed. The magnitude of a standard deviation is based on the 1961-2005 period. Bar plots compare the frequency of extreme years when interannual anomalies in AMJ (b) vapor pressure, (d) saturation vapor pressure, and (f) VPD are strong enough to positively force VPD by at least $10 \%$ of the $1961-2005$ mean. Double asterisks above the bar plots indicate significant $(p<$ 0.01 ) differences in simulated frequencies of extreme years for the two time periods.

warming and suppressed increases in atmospheric moisture content alone are projected to contribute to an increased frequency of years in which VPD matches or exceeds 2011 levels. Superimposed upon the projected increase in mean VPD, interannual variations of temperature and dewpoint (e.g., departures of dewpoint from the projected trend line in Fig. 8) will have increasingly amplified effects on interannual VPD anomalies because of the exponential relationship between temperature and saturation vapor pressure. Figure 10 demonstrates how VPD would be influenced by a 2011type event in the 2050s, where observed 2011 


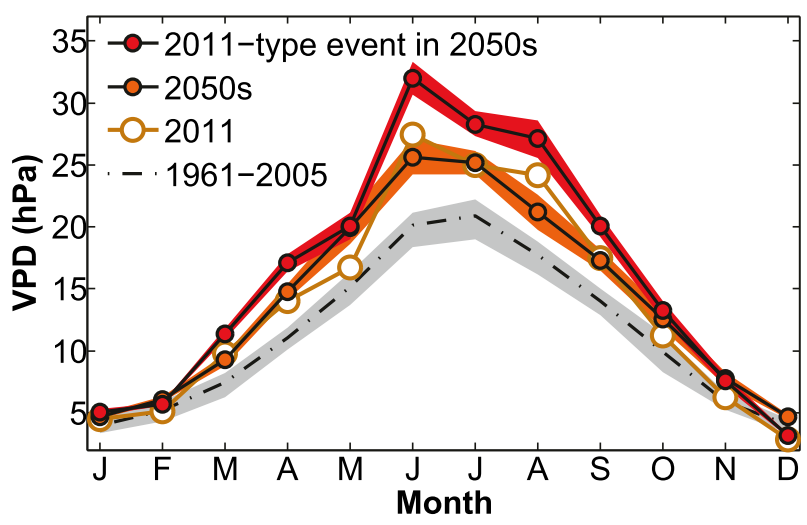

FIG. 10. Annual VPD cycle. Annual cycles for 1961-2005 and 2011 represent observed data. Gray shading bounds inner quartiles of 1961-2005 annual values. Annual cycles for 2050s represent CMIP5 ensemble means (lines and circles) and inner quartiles (shading). For the case of the 2011-type event in the 2050s, 2011 temperature and dewpoint anomalies were superimposed upon 2050s modeled temperature and dewpoint.

temperature and dewpoint anomalies are superimposed upon mean 2050s levels. For March-August, the period when VPD correlates most strongly with SW burned forest area (Williams et al. 2014), a 2011-type event in the 2050s would cause VPD to be $47 \%$ higher than the 1961-2005 average and 16\% higher than in 2011.

\section{Summary and conclusions}

The year 2011 was interesting in terms of droughtrelated climate impacts in the SW because it was not exceptionally warm throughout the parts of Arizona and New Mexico where record-breaking forest fires occurred. VPD, on the other hand, was record breaking in these areas because of exceptionally low atmospheric moisture content. Abatzoglou and Kolden (2013) and Williams et al. (2014) showed that SW annual burned area is closely tied to spring-summer potential evapotranspiration, VPD, and moisture deficit. These studies make it clear that record-breaking wildfire activity in 2011 was very likely promoted by record-low precipitation and record-high VPD.

It is interesting that VPD, which is normally dominated by temperature, was substantially amplified in 2011 by extremely low atmospheric moisture content. The meteorological conditions responsible for extremely low atmospheric moisture in 2011 were driven by an interaction of atmospheric, oceanic, and land surface conditions. Among the most important contributing factors appear to have been record-setting low precipitation totals and a record-setting strong sea level pressure gradient between the North Pacific Ocean and North America that drove dry northwesterly wind and subsidence anomalies toward the SW throughout the troposphere. Subsidence over the SW was enhanced by upper-level convergence associated with the La Niña-forced atmospheric wave train. Subsidence aloft led to divergence of dry, loweratmospheric winds across Arizona and much of New Mexico, blocking advection of moist air from both the subtropical Pacific and the Gulf of Mexico. Convergence of warm, dry winds in eastern New Mexico and western Texas interacted with exceptionally dry soils to cause recordbreaking heat, further amplifying VPD in these areas.

Model projections suggest that 2011 conditions were representative of projected future climate in limited ways. CMIP5 climate projections tend to agree upon an enhanced sea level pressure gradient between the North Pacific and North America, an enhanced upper-level pressure gradient between Mexico and the Pacific Northwest that drives convergence and subsidence upwind of and above the SW, a more negative PDO, and lower October-June precipitation totals. As atmospheric moisture content increases with warming globally, projected trends in the variables listed here combine to slow the projected atmospheric moisture increases in the SW, thereby allowing for an amplified influence of background VPD levels. These projections do not necessarily indicate an increased frequency of 2011-type circulation extremes, but they nonetheless positively influence the frequency with which 2011 levels of VPD are achieved in the CMIP5 projections. Further, CMIP5 models generally project the interannual variability of SW dewpoint, temperature, vapor pressure, saturation vapor pressure, and VPD to increase independent of background trends, suggesting that large negative deviations of VPD from the background trend, such as that which occurred in 2011, will become increasingly probable. Increased interannual variability in dewpoint amplifies the increase in interannual VPD variability that is already expected as a result of the exponential Clausius-Clapeyron response to warming alone.

Although the exceptional negative atmospheric moisture anomaly in spring-summer 2011 was unprecedented in the observed record, CMIP5 projections suggest that extreme 2011-like deviations in atmospheric moisture content from background levels will become increasingly probable as the globe warms. Recurrences of 2011-type events in which temperature and atmospheric moisture deviations combine to substantially amplify VPD will be superimposed upon increasingly warm background temperatures that, on their own, will drive substantial increases in SW VPD. By the 2050s, average spring-summer VPD is projected to surpass that of 2011. Strong and nonlinear relationships among temperature, VPD, and SW burned area (Williams et al. 2014) suggest that 2011-type 
precipitation and circulation anomalies, superimposed upon substantially warmer background conditions, could have far more catastrophic wildfire consequences than they did in the record-breaking wildfire year of 2011 if fuel characteristics are not limiting.

Acknowledgments. This work was supported by the Los Alamos National Laboratory (LANL) Laboratory Directed Research and Development program and the U.S. Department of Energy (DOE) Biological and Environmental Research program. Author RS was supported by NOAA awards NA10OAR4310137 (Global Decadal Hydroclimate Variability and Change) and NSF Award EASM2: Linking Near-term Future Changes in Weather and Hydroclimate in Western North America to Adaptation for Ecosystem and Water Management. Thanks are given to C. D. Allen, C. Baisan, C. Daly, D. Griffin, R. Linn, and S. A. Rauscher for helpful conversations and insights.

\section{REFERENCES}

Abatzoglou, J. T., and C. A. Kolden, 2013: Relationships between climate and macroscale area burned in the western United States. Int. J. Wildland Fire, 22, 1003-1020, doi:10.1071/ WF13019.

Anderson, D. B., 1936: Relative humidity or vapor pressure deficit. Ecology, 17, 277-282, doi:10.2307/1931468.

Ault, T. R., A. K. Macalady, G. T. Pederson, J. L. Betancourt, and M. D. Schwartz, 2011: Northern Hemisphere modes of variability and the timing of spring in western North America. J. Climate, 24, 4003-4014, doi:10.1175/2011JCLI4069.1.

Crimmins, M. A., 2010: Interannual to decadal changes in extreme fire weather event frequencies across the southwestern United States. Int. J. Climatol., 31, 1573-1583.

Dettinger, M. D., D. R. Cayan, H. F. Diaz, and D. M. Meko, 1998: North-south precipitation patterns in western North America on interannual-to-decadal timescales. J. Climate, 11, 3095-3111, doi:10.1175/1520-0442(1998)011<3095:NSPPIW>2.0.CO;2.

Fischer, E. M., S. I. Seneviratne, P. L. Vidale, D. Lüthi, and C. Schär, 2007: Soil moisture-atmosphere interactions during the 2003 European summer heat wave. J. Climate, 20, 50815099, doi:10.1175/JCLI4288.1.

Hamlet, A. F., and D. P. Lettenmaier, 2005: Production of temporally consistent gridded precipitation and temperature fields for the continental United States. J. Hydrometeor., 6, 330-336, doi:10.1175/JHM420.1.

Hoerling, M., and Coauthors, 2013: Anatomy of an extreme event. J. Climate, 26, 2811-2832, doi:10.1175/JCLI-D-12-00270.1.

Lapp, S. L., J. M. St Jacques, E. M. Barrow, and D. J. Sauchyn, 2012: GCM projections for the Pacific decadal oscillation under greenhouse forcing for the early 21 st century. Int. J. Climatol., 32, 1423-1442, doi:10.1002/joc. 2364.

Littell, J. S., D. McKenzie, D. L. Peterson, and A. L. Westerling, 2009: Climate and wildfire area burned in western US ecoprovinces, 1916-2003. Ecol. Appl., 19, 1003-1021, doi:10.1890/07-1183.1.

Mantua, N. J., S. R. Hare, Y. Zhang, J. M. Wallace, and R. C. Francis, 1997: A Pacific interdecadal climate oscillation with impacts on salmon production. Bull. Amer. Meteor.
Soc., 78, 1069-1079, doi:10.1175/1520-0477(1997)078<1069: APICOW $>2.0 . \mathrm{CO} ; 2$.

Mesinger, F., and Coauthors, 2006: North American Regional Reanalysis. Bull. Amer. Meteor. Soc., 87,343-360, doi:10.1175/ BAMS-87-3-343.

Miller, P., 2012: Weather gone wild. Natl. Geogr. Mag., 222 (3), 3053. [Available online at http://ngm-beta.nationalgeographic. com/2012/09/issues/september-20121/.]

Mitchell, K. E., and Coauthors, 2004: The multi-institution North American Land Data Assimilation System (NLDAS): Utilizing multiple GCIP products and partners in a continental distributed hydrological modeling system. J. Geophys. Res., 109, D07S90, doi:10.1029/2003JD003823.

Moss, R. H., and Coauthors, 2010: The next generation of scenarios for climate change research and assessment. Nature, 463, 747756, doi:10.1038/nature08823.

Nijhuis, M., 2012: Forest fires: Burn out. Nature, 489, 352-354, doi:10.1038/489352a.

Rienecker, N. M., and Coauthors, 2011: MERRA: NASA's ModernEra Retrospective Analysis for Research and Applications. J. Climate, 24, 3624-3648, doi:10.1175/JCLI-D-11-00015.1.

Rupp, D. E., P. W. Mote, N. Massey, C. J. Rye, R. Jones, and M. R. Allen, 2012: Did human influence on climate make the 2011 Texas drought more probable? Bull. Amer. Meteor. Soc., 93, 1052-1054.

Seager, R., L. Goddard, J. Nakamura, N. Henderson, and D. E. Lee, 2014a: Dynamical causes of the 2010/11 Texas-northern Mexico drought. J. Hydrometeor., 15, 39-68, doi:10.1175/ JHM-D-13-024.1.

—, and Coauthors, 2014b: Dynamical and thermodynamical causes of large-scale changes in the hydrological cycle over North America in response to global warming. J. Climate, 27, 7921-7948, doi:10.1175/JCLI-D-14-00153.1.

Sheffield, J., G. Goteti, and E. F. Wood, 2006: Development of a 50-year high-resolution global dataset of meteorological forcings for land surface modeling. J. Climate, 19, 3088-3111, doi:10.1175/JCLI3790.1.

Swetnam, T. W., and J. L. Betancourt, 1990: Fire-Southern Oscillation relations in the southwestern United States. Science, 249, 1017-1020, doi:10.1126/science.249.4972.1017.

$\ldots$, and - 1998: Mesoscale disturbance and ecological response to decadal climatic variability in the American southwest. J. Climate, 11, 3128-3147, doi:10.1175/ 1520-0442(1998)011<3128:MDAERT>2.0.CO;2.

Trenberth, K. E., 1984: Signal versus noise in the Southern Oscillation. Mon. Wea. Rev., 112, 326-332, doi:10.1175/ 1520-0493(1984)112<0326:SVNITS > 2.0.CO;2.

van Vuuren, D. P., and Coauthors, 2011: The representative concentration pathways: An overview. Climatic Change, 109, 5-31, doi:10.1007/s10584-011-0148-z.

Wallace, J. M., and D. S. Gutzler, 1981: Teleconnections in the geopotential height field during the Northern Hemisphere winter. Mon. Wea. Rev., 109, 784-812, doi:10.1175/ 1520-0493(1981)109<0784:TITGHF > 2.0.CO;2.

Westerling, A. L., and T. W. Swetnam, 2003: Interannual to decadal drought and wildfire in the western United States. Eos, Trans. Amer. Geophys. Union, 84, 545-554, doi:10.1029/ 2003EO490001.

, A. Gershunov, T. J. Brown, D. R. Cayan, and M. D. Dettinger, 2003: Climate and wildfire in the western United States. Bull. Amer. Meteor. Soc., 84, 595-604, doi:10.1175/BAMS-84-5-595.

—, H. G. Hidalgo, D. R. Cayan, and T. W. Swetnam, 2006: Warming and earlier spring increase western US forest wildfire activity. Science, 313, 940-943, doi:10.1126/science.1128834. 
Williams, A. P., and Coauthors, 2013: Temperature as a potent driver of regional forest drought stress and tree mortality. Nat. Climate Change, 3, 292-297, doi:10.1038/nclimate1693.

—_, and Coauthors, 2014: Correlations between components of the water balance and burned area reveal new insights for predicting fire activity in the southwest US. Int. J. Wildland Fire, doi:10.1071/ WF14023, in press.

Xia, Y., and Coauthors, 2012: Continental-scale water and energy flux analysis and validation for the North American Land Data Assimilation System project phase 2
(NLDAS-2): 1. Intercomparison and application of model products. J. Geophys. Res., 117, D03109, doi:10.1029/ 2011JD016048.

Zaitchik, B. F., A. K. Macalady, L. R. Beonneau, and R. B. Smith, 2006: Europe's 2003 heat wave: A satellite view of impacts and land-atmosphere feedbacks. Int. J. Climatol., 26, 743-769, doi:10.1002/joc.1280.

Zhang, Y., J. M. Wallace, and D. S. Battisti, 1997: ENSO-like interdecadal variability: 1900-93. J. Climate, 10, 1004-1020, doi:10.1175/1520-0442(1997)010<1004:ELIV>2.0.CO;2. 